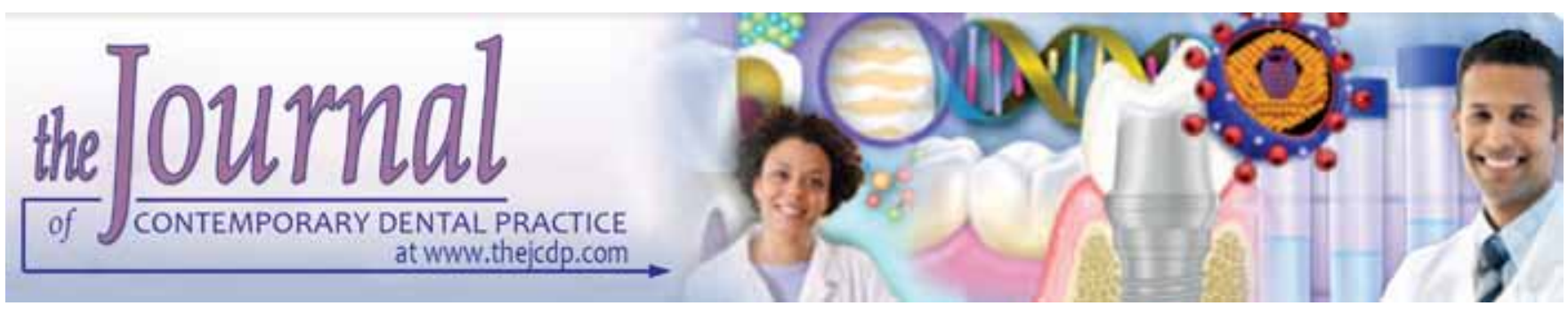

\title{
A Comparative Evaluation of Shear Bond Strength of Different Pits and Fissure Sealants: An in vitro Study
}

Nitin Singh, Govind Agrawal, AV Subhash, S Suneela, Aparna S Barabde, G Ajay Kumar

\section{ABSTRACT}

Aim: The aim of this study was to determine and compare the shear bond strength of three different pits and fissure sealants to enamel namely, Delton, Clinpro and Z350 Filtek flowable composite.

Materials and methods: Ninety permanent molars were divided into three groups of 30 each. Their proximal surfaces were prepared and stored in $37^{\circ} \mathrm{C} \pm 5^{\circ} \mathrm{C}$ normal saline for 24 hours. Sealant buttons were prepared. The specimens were tested in a shear mode (Lloyds LR100K) at a crosshead speed of $0.5 \mathrm{~mm} / \mathrm{min}$. The mean and standard deviations were subjected to an analysis of variance.

Results: The mean shear bond strength of samples of Delton was $10.33 \mathrm{MPa}$; Clinpro was $8.51 \mathrm{MPa}$ and Z350 Filtek flowable was $12.17 \mathrm{MPa}$. The mean strength of Delton was significantly higher as compared to Clinpro whereas the mean strength of Z350 Filtek was significantly higher as compared to Delton and Clinpro (Student t-test, $p<0.001$ ).

Conclusion: Z350 Filtek flowable composite had maximum shear bond strength than Delton FS sealant followed by Clinpro sealant.

Clinical significance: In this study, we compare the bond strength of three pits and fissure sealant, Clinpro yielded lower bond strength than Delton. This outcome can be described due to the presence of fillers in Delton, since these particles increase the resistance of the material to abrasion and also increase the mechanical resistance of the material.

Keywords: Pits and fissures, Pits and fissure sealants, Shear bond strength, Sealants, Nanofillers.

How to cite this article: Singh N, Agrawal G, Subhash AV, Suneela S, Barabde AS, Kumar GA. A Comparative Evaluation of Shear Bond Strength of Different Pits and Fissure Sealants: An in vitro Study. J Contemp Dent Pract 2013;14(5):917-923.

\section{Source of support: Nil}

Conflict of interest: None declared

\section{INTRODUCTION}

Pits and fissure are defects that occur on occlusal surface of molars and premolars with tortuous configuration that are difficult to assess from the surface. The narrow width and uneven depth make them vulnerable for acid producing bacteria to accumulate. Saliva, which helps to clean food particles from other areas of the mouth, even cannot clean pits and fissures in molars. A toothbrush bristle is too large to enter and clean most fissures thus, making them highly susceptible to advancement of the carious lesion.

Among surfaces of crown of posteriors, the occlusal surface with pits and fissure shows more carious involvement than other surfaces. Twelve and a half percent of all the different tooth surfaces in the mouth are occlusal surfaces. These surfaces develop more than two-thirds of the total caries experienced by children. Because of high incidence of caries process, the concept of extension for prevention as an adjunct procedure was developed. Different preventive techniques involving clinical methods and restorative materials were evolved for the sake of caries prevention. Newer approaches were continuously being developed including fluoride application and use of sealants. ${ }^{1}$

The sealant acts as a physical barrier in preventing oral bacteria and dietary carbohydrates from creating the acid conditions that result in caries. Placement of a sealant is a noninvasive technique that maintains tooth integrity while providing an acceptable resolution of the carious process. Caries activity in sealed carious lesions decreases dramatically with time. Radiographs show that not only the caries will cease beneath a properly placed sealant, but also that a lesion will inadvertently be arrested. ${ }^{2,3}$

In the longest clinical study done on sealant retention, $83 \%$ effectiveness was seen against caries after 1 year and $53 \%$ after 15 years. A study suggests that after placing sealants in 3- to 4-year-old children after a mean period of 2.8 years caries was found in less than $10 \%$ of children. NHANES III survey (1988-1994) concluded that 62 to $82 \%$ reduction in pit and fissure caries was seen after pits and fissure sealant application., ${ }^{4,5}$ 
If the sealants are placed, maintained and reapplied when necessary the children could have been caries-free. A reapplication every 6 months, if needed, is recommended. ${ }^{6}$ We, as pedodontist, have to be judicious in using pits and fissure sealant to aid in producing a caries-free world.

Therefore, the present study was conducted with an aim to determine and compare the shear bond strength of three different pits and fissure sealants to enamel namely, Delton, Clinpro and Z350 Filtek flowable composite.

\section{MATERIALS AND METHODS}

The present in vitro study was conducted on 90 caries free surfaces of permanent molars (Fig. 1), extracted for periodontal reasons or orthodontic purposes. On each tooth, sealant buttons were prepared; on either side of the proximal surface the teeth selected were cleaned with hand scalers to remove necrotic tissues, blood debris, stains and calculus. They were then washed with toothbrush under running tap water.

The mesial or distal surfaces were cleaned with pumice slurry with the help of rubber cup through slow speed micromotor to remove smear layer. ${ }^{7}$ The samples were then stored in normal saline at $37^{\circ} \mathrm{C} \pm 5^{\circ} \mathrm{C}$ temperature. ${ }^{8}$ The various material used in this study are placed in table (Table 1).

\section{DISTRIBUTION OF GROUPS}

Teeth were randomly divided into three groups; group 1, group 2 and group 3. Each group was having 30 samples of teeth (Fig. 2) (Table 2).

Group 1: In group 1, fluoride releasing glass filled (55\%) resin-based sealant was used (Delton).

Group 2: In group 2, fluoride releasing unfilled resinbased sealant was used (Clinpro).

Group 3: In group 3, nanoparticle filled (65\%) resinbased sealant was used (Z350 Filtek flowable composite).

Each group of teeth was treated with $37 \%$ phosphoric acid etchant as per manufacturer's instructions.

Caries free middle segment of mesial or distal surfaces was chosen for the preparation of sealant core to standardize the site of bonding of specimen.

A plastic ring of $3 \mathrm{~mm}$ internal diameter and $3 \mathrm{~mm}$ height was taken and placed over the enamel, ${ }^{9,10}$ perpendicular to the prepared mesial or distal surface of teeth to ensure standardization of shape and size of sealant button. The remaining surface was covered with adhesive tape to prevent overflow of sealant from the interface of tooth and plastic mold.

After ring placement $37 \%$ phosphoric acid (EZ etchant) ${ }^{11}$ was used to etch the enamel surface within the concise area

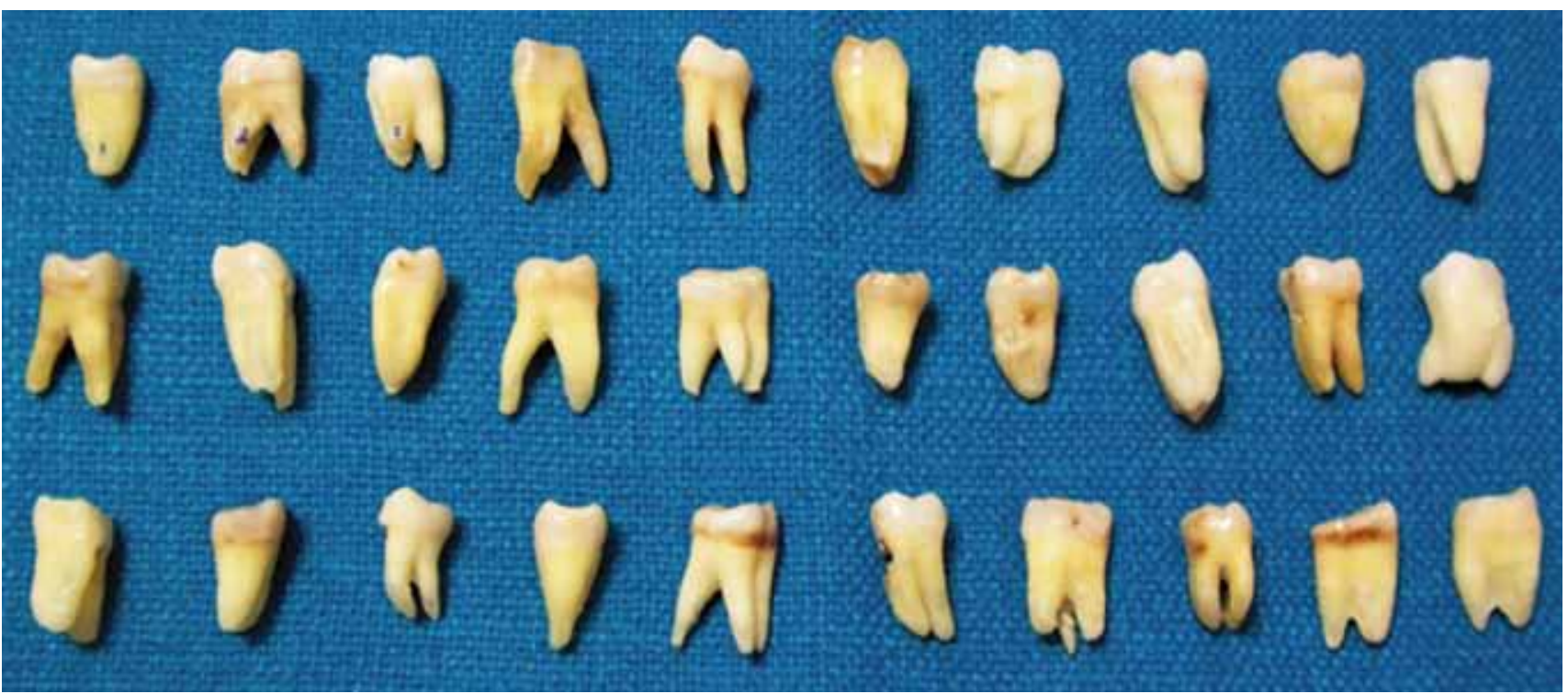

Fig. 1: Caries free surfaces of permanent molars

\begin{tabular}{|c|c|c|c|c|}
\hline \multicolumn{5}{|c|}{ Table 1: Material profile } \\
\hline S. no & Materials & Description & Batch no & Manufacturer \\
\hline 1. & Delton & $\begin{array}{l}\text { Fluoride-releasing glass } \\
(55 \%) \text { filled resin sealant }\end{array}$ & Lot no. 070915 & $\begin{array}{l}\text { Dentsply International York, } \\
\text { PA }\end{array}$ \\
\hline 2. & Clinpro & $\begin{array}{l}\text { Fluoride-releasing unfilled } \\
\text { resin sealant }\end{array}$ & ID no. $70-2010-3150-0$ & $\begin{array}{l}\text { 3M ESPE Dental Products, } \\
\text { St. Paul, MN, USA }\end{array}$ \\
\hline 3. & $\begin{array}{l}\text { Z350 Filtek flowable } \\
\text { composite }\end{array}$ & $\begin{array}{l}\text { Nanoparticle }(65 \%) \text { filled } \\
\text { sealant }\end{array}$ & ID no. $70-2010-1609-7$ & $\begin{array}{l}\text { 3M ESPE Dental Products, } \\
\text { St. Paul, MN, USA }\end{array}$ \\
\hline 4. & EZ Etchant & $37 \%$ phosphoric acid & Lot no. 0707252 & $\begin{array}{l}\text { Dentsply } \\
\text { International York, PA }\end{array}$ \\
\hline
\end{tabular}




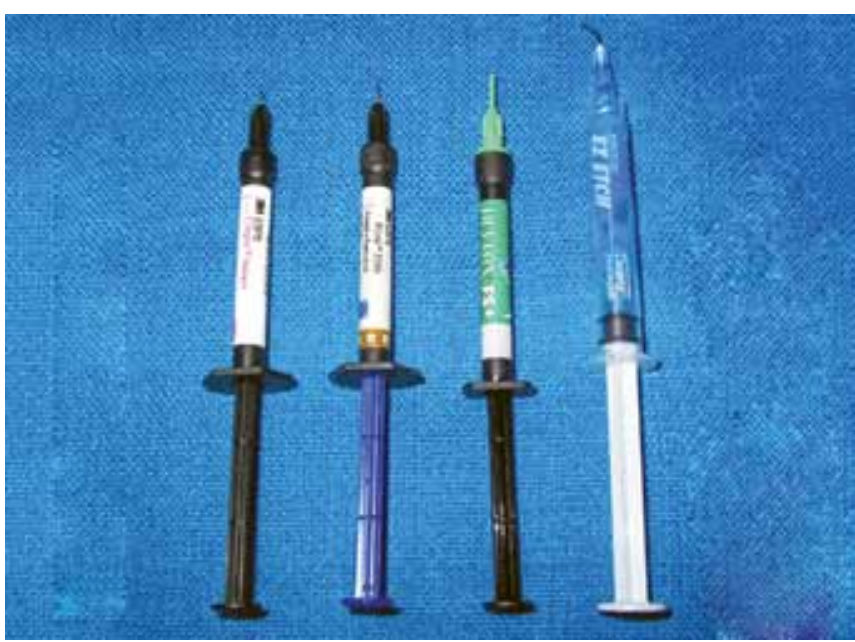

Fig. 2: Group1 (Delton) group 2 (Clinpro) and group 3 (Z350 Filtek)

\begin{tabular}{lll} 
& Table 2: Group distribution \\
\hline Group 1 & Group 2 & Group 3 \\
\hline Delton & Clinpro & Z 350 Filtek \\
37\% phosphoric & $37 \%$ phosphoric & $37 \%$ phosphoric \\
acid & acid & acid \\
\hline
\end{tabular}

of the ring for 60 seconds, ${ }^{12,13}$ followed by rinsing with water for 20 seconds and then oil-free air drying with chip blower for 30 seconds till smooth chalky white surface was achieved.

The respective sealants of each group were filled into the plastic mold (Fig. 3) and cured for 30 seconds time with the light cure gun from the top as per manufacturer's instruction.

After curing, the plastic molds were cut with scalpel blade and sealant core teeth sample were removed and embedded in hard plaster, in plastic ring of 1 inch internal diameter and 2 inches of length at long axis of teeth to make plaster blocks. The specimens were stored in normal saline for 24 hours to avoid dehydration and were subjected for analysis in Lloyds LR100K universal testing machine (Fig. 4). ${ }^{14}$

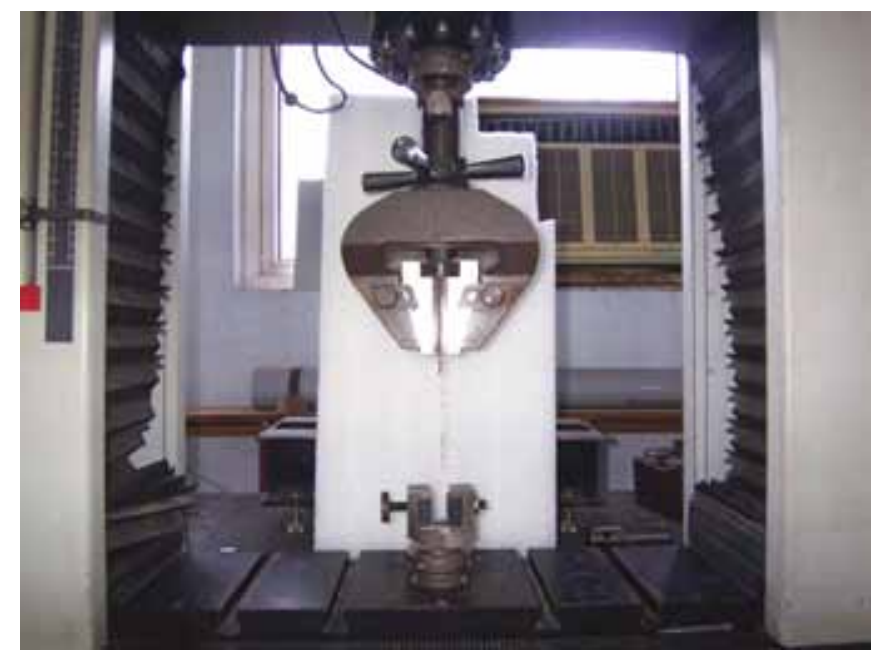

Fig. 4: Lloyds LR100K universal testing machine

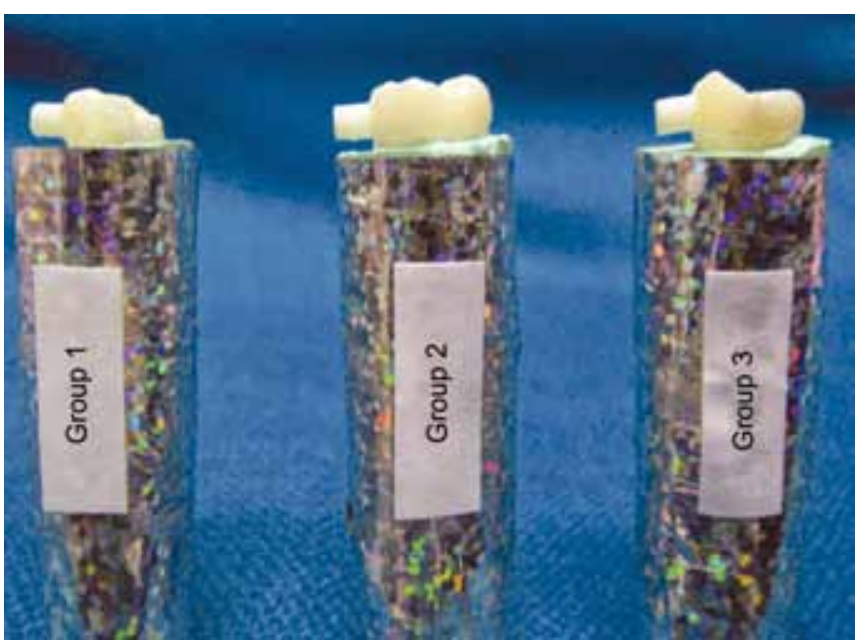

Fig. 3: Sealants of each group were filled into the plastic mold and cured

Shear bond strength of the prepared sealant core samples were tested using Lloyds LR100K universal testing machine. A knife edge chisel was used, which contacted the area of bonding between sealant mold and the tooth surface. The chisel was attached to crosshead of universal testing machine (Figs 5 and 6).

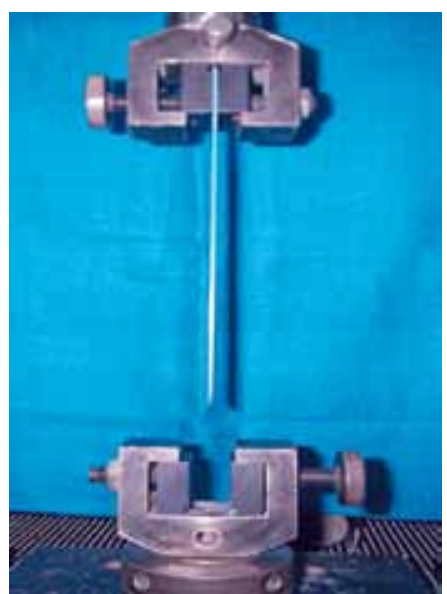

Fig. 5: Crosshead of Lloyds LR100K universal testing machine

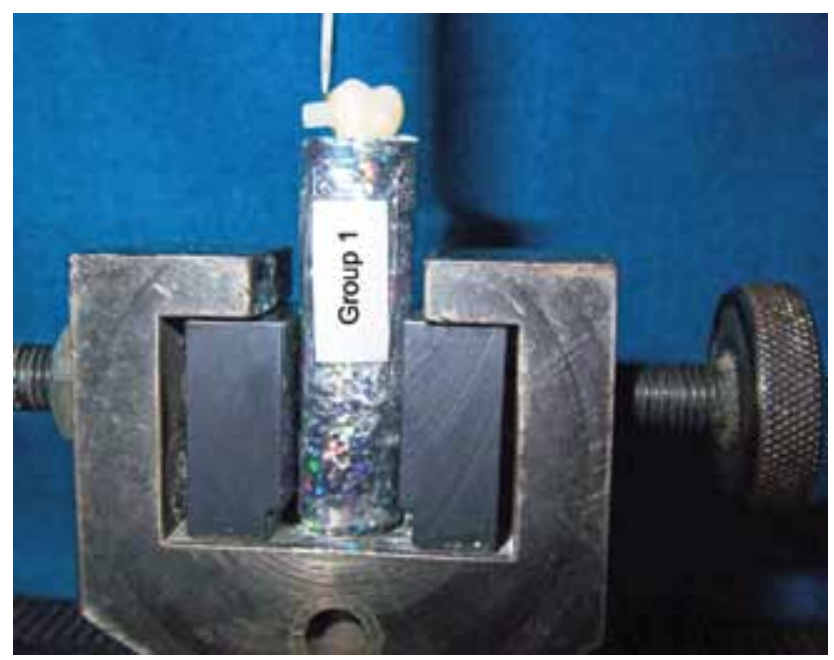

Fig. 6: Chisel at the crosshead speed of $0.5 \mathrm{~mm} / \mathrm{min}$ of Lloyds LR100K universal testing machine 
A shearing force was applied perpendicular to the prepared sealant surface with testing chisel at the crosshead speed of $0.5 \mathrm{~mm} / \mathrm{min}$.

The load at which the sealant mold was debonded from the tooth surface was noted from the device and computer, attached to the universal testing machine and values were recorded in Newton. It was then converted to Mega Pascal (MPa) with the help of conversion formula.

For the purpose of statistical analysis, the data obtained was fed into computer and analyzed using statistical package for social sciences (SPSS) Version 15.0. Analysis of variance (ANOVA) and independent sample ' $t$ '-test were performed.

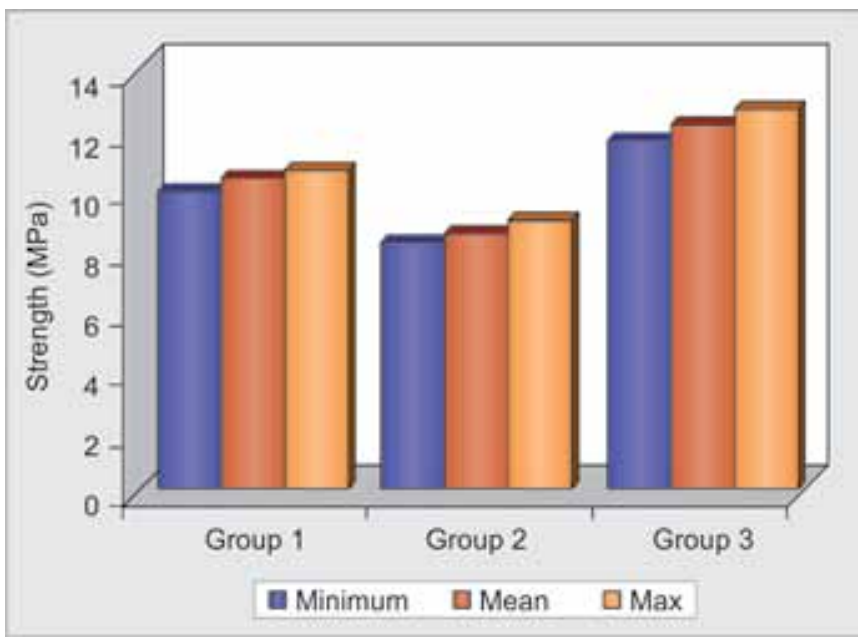

Graph 1: Bar diagram showing comparison of forces applied to break the sealant button from the tooth surface in three groups under study

\section{RESULTS}

The differences among groups were broad as was evident by the range of force applied in the three groups (Table 3) (Graph 1).

\begin{tabular}{lrcc}
\multicolumn{4}{c}{$\begin{array}{c}\text { Table 3: Mean force applied to break the sealant button from } \\
\text { the tooth surface in three groups under study }\end{array}$} \\
\hline & Group 1 & Group 2 & Group 3 \\
\hline Number of specimen & 30 & 30 & 30 \\
Mean force applied & 10.33 & 8.51 & 12.17 \\
Standard deviation & 0.16 & 0.20 & 0.29 \\
Median & 10.32 & 8.51 & 12.20 \\
Minimum & 9.93 & 8.22 & 11.63 \\
Maximum & 10.57 & 8.95 & 12.67 \\
\hline
\end{tabular}

While in group 1 the minimum to maximum range was 9.93 to $10.57 \mathrm{MPa}$, in group 2 it was 8.22 to $8.95 \mathrm{MPa}$ and in group 3 between 11.63 and $12.67 \mathrm{MPa}$, showing a limited scope for overlapping forces.

On comparing the variance among the groups (Table 4), the F-ratio was calculated as 1959.052 which was statistically highly significant $(p<0.001)$ at degree of freedom 89 . The ANOVA thus revealed a statistically significant difference among the groups.

The line diagram above clearly depicts that all the values of group 1 fall within the range 9.9 to $10.6 \mathrm{MPa}$, whereas all the values of group 2 fall within the range 8.2 to $9.0 \mathrm{MPa}$, and similarly all the values of group 3 fall within the range 11.5 to $12.7 \mathrm{MPa}$, thus there is almost no chance of deviation of the values from one range category to another, that is why there are highly significant differences between the groups.

Similar observations have been reflected in the line diagram (Graph 2).

The mean strength of group 1 was significantly higher as compared to group $2(p<0.001)$. The mean strength of group 3 was significantly higher as compared to group 1 (p $<0.001)$ and the mean strength of group 3 was significantly higher as compared to group $2(\mathrm{p}<0.001)$ (Table 5).

On the basis of above results and statistical analysis the strength of the three groups could be depicted as: Group 3 $>$ Group $1>$ Group 2.

\section{DISCUSSION}

Acid etching causes optimization of tooth surface by removal of smear debris, i.e. the barrier layer on tooth surface and dissolution of biological apatite crystals from enamel that means the selective removal of substrate components thus making smooth surface to an irregular one. It also modifies surface energy, which reduces the contact angle. The contact angle is inverse measure of the wettability of the surface, which increases bonding and produces better interfacial contact between resin and enamel. The contact angle of uncured epoxy resin was reduced from a mean value of 28.3 to 14.3 after conditioning of surface. ${ }^{15,16}$

\begin{tabular}{clcc}
\multicolumn{4}{c}{ Table 5: Intergroup comparison } \\
S. no. & Comparison & 't' & ' $p '$ \\
\hline 1. & Groups 1 vs 2 & 38.190 & $<0.001$ \\
2. & Groups 1 vs 3 & -30.041 & $<0.001$ \\
3. & Groups 2 vs 3 & -56.308 & $<0.001$ \\
\hline
\end{tabular}

\begin{tabular}{lccccc}
\multicolumn{5}{c}{ Table 4: ANOVA in three groups under study } \\
\hline & Sum of squares & $d f$ & Mean square & $F$ & Significance \\
\hline Between groups (Combined) & $10,048.423$ & 2 & 5024.211 & 1959.052 & $<0.001$ \\
Within groups & 223.121 & 87 & 2.565 & & \\
\hline Total & $10,271.544$ & 89 & & \\
\hline
\end{tabular}




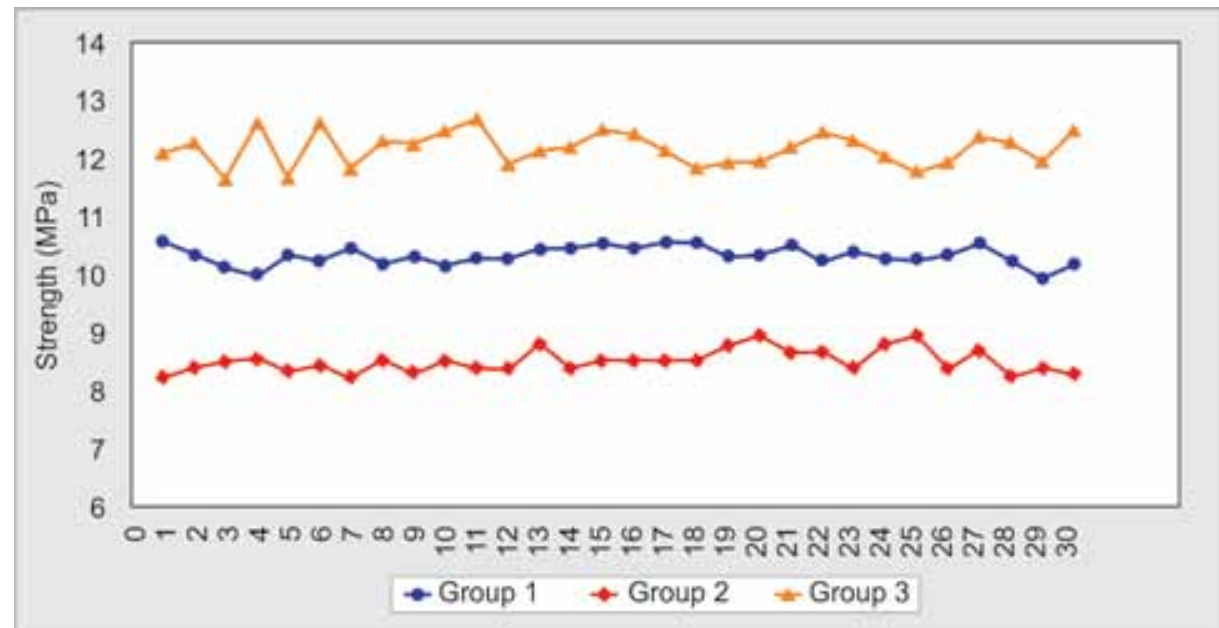

Graph 2: Line diagram showing comparison of mean force applied to break the sealant button from the tooth surface in three groups under study

Phosphoric acid is widely used for enamel etching in the range of 35 to $40 \%$ concentration. The acid should be used in proper concentration to prevent the formation of precipitates that could interfere with adhesion. ${ }^{17}$ Application of $50 \%$ phosphoric acid for 60 seconds results in formation of a monocalcium phosphate monohydrate precipitate that could be rinsed off. However, concentration below 27\% may create dicalcium phosphate dihydrate precipitate, which cannot be easily removed and may interfere with the adhesion. Application of 30 to $40 \%$ phosphoric acid results in very retentive enamel surface.

Sound enamel after etching with phosphoric acid produces changes at microscopic level. Three zones are formed. In first zone, a narrow zone of enamel is removed by etching; it also removes plaque, surface and subsurface organic pellicle and inert mineral crystals which result in a more reactive surface, increased surface area and reduced surface tension that allow resin to wet the etched enamel more readily. This zone is approximately $10 \mu \mathrm{m}$ in depth. The second zone is qualitative porous zone; it consists of large porosities and is $20 \mu \mathrm{m}$ in depth. The final zone is quantitative porous zone, which consists of large porosities and is $20 \mu \mathrm{m}$ in depth. When pits and fissure sealant material is applied to etched enamel the sealants do not bond but penetrates into the microporosities and form resin tags. These resin tags penetrate to a depth of 25 to $50 \mu \mathrm{m}$ whereas some of the resin tags penetrate to a depth of $100 \mu \mathrm{m}$ and are retained due to micromechanical bond. The length of resin tags may increase three times, by allowing visible light resin to penetrate into the microporosities for 20 seconds or more prior to curing reaction. ${ }^{18}$

The pits and fissure sealant retention depends upon the penetration of the sealant into occlusal fissure and filler load that increases the resistance of sealant into the tooth surface.
Resins can be classified on the basis of filler particle size. Filler particles are called macrofill from 10 to $100 \mu \mathrm{m}$, midfill from 1 to $10 \mu \mathrm{m}$, minifill from 0.1 to $1 \mu \mathrm{m}$, microfill from 0.01 to $0.1 \mu \mathrm{m}$, nanofill from 0.005 to $0.01 \mu \mathrm{m} .{ }^{19}$

Nanofillers are so small that they fit between several polymer chains. This permits the opportunity to achieve very high filler loading levels in composites while maintaining workable consistencies. The filler particle size, distribution and quantity incorporated, influenced the mechanical and physical properties. ${ }^{20}$ Nanocomposites have equivalent or higher compressive, diametral and flexural strength with better fracture resistance than conventional composites. ${ }^{21}$

The purpose of breaking a bonded assembly is to try to establish a number or value showing how strong the bond. was. In shear bond test, the bond is broken by a force working parallel to the surface. The ISO document specified a shear test apparatus consisting of a solid block for fixation of the specimen and a connecting shearing blade with sharp edge. Bond strength is more predictive of materials retentive potential, hence about its durability and utility. ${ }^{22}$

The mean bond strength of Delton FS filled sealant (group 1) was $10.33 \mathrm{MPa}$ with standard deviation of \pm 0.16 $\mathrm{MPa}$, similar results were reported with bond strength of $11.83 \mathrm{MPa}$, which was comparable to the present study. Other study presented bond strength value of $9.36 \mathrm{MPa}$, which were without any significant difference, found no difference in bond strength of sealant when compared to self-etching adhesive and $35 \%$ phosphoric acid. ${ }^{23,24}$

Comparable bond strength of $12.39 \mathrm{MPa}$ after cleaning and polishing enamel surface with pumice was reported. ${ }^{25}$ And other study reported slightly higher values of $13.7 \mathrm{MPa}$ after enamel surface being grounded by 180 to 400 Grit silicon carbide paper and polished by 600 Grit paper for 30 seconds to obtain standardized smear layer which resulted in increased mechanical bond but also removed extra enamel surface. 
The mean bond strength of Clinpro unfilled sealant (group 2) was $8.51 \mathrm{MPa}$ with standard deviation of $\pm 0.20 \mathrm{MPa}$. Other study reported bond strength of $9.17 \mathrm{MPa}$, which were comparable to the present study.

The mean bond strength of Z350 Filtek nanofilled sealant (group 3) was $12.17 \mathrm{MPa}$ with standard deviation of $\pm 0.29 \mathrm{MPa}$. The higher result was yielded due to the presence of nanofiller particles that were dramatically smaller, could be dissolved in higher concentrations, and were polymerized into resin system with molecules designed to be compatible when coupled with polymer, to provide optimal adhesion to the mineralized hard tissue thereby enhancing the mechanical strength, marginal adaptation and seal thus improving the reliability and longevity of adhesive restoration. ${ }^{20}$

If we compare the bond strength of three pits and fissure sealant, Clinpro yielded lower bond strength than Delton. This outcome can be described due to the presence of fillers in Delton, since these particles increase the resistance of the material to abrasion ${ }^{25}$ and also increase the mechanical resistance of the material. The main difference between the tested sealants relies on presence or absence of fillers, since both materials are resin based and contains fluoride in their composition.

The filled sealants unlike unfilled sealants have inorganic fillers in their composition that makes them of higher viscosity. This impairs the a bility of these sealants to flow into pits and fissures close to the bottom because of which shorter resin tags are formed. ${ }^{35}$ But the presence of fillers in the sealant increase the resistance of the resin tags produced.

Z350 Filtek yielded higher bond strength when compared to Clinpro and Delton sealants because it contained two additional nonagglomerated/nonaggregated nanofillers. One, was a $75 \mathrm{~nm}$ nonagglomerated/nonaggregated silica nanofiller and the other was 5 to $10 \mathrm{~nm}$ diameter zirconia nanofiller, these nanofillers contributed to higher and more uniform filler density within the resin, surrounding the micron and submicron nanocluster. This optimized interstitial filler architecture, contributed to excellent physical, wear and polish properties. ${ }^{21}$

\section{CONCLUSION}

Within the limits of this in vitro study and according to the methodology and the results drawn the following statements were concluded that Z350 Filtek (group 3) had maximum shear bond strength value of $12.17 \mathrm{MPa}$, Delton FS sealant (group 1) had shear bond strength value of $10.33 \mathrm{MPa}$ and Clinpro sealant (group 2) had minimum shear bond strength value of $8.51 \mathrm{MPa}$.

\section{CLINICAL SIGNIFICANCE}

In this study, we compared the bond strength of three pits and fissure sealant, Clinpro yielded lower bond strength than Delton. This outcome can be described due to the presence of fillers in Delton, since these particles increase the resistance of the material to abrasion and also increase the mechanical resistance of the material.

\section{REFERENCES}

1. Fiegal RJ. Current status of pit and fissure sealants: improving effectiveness of the preventive strategy. J Pediatr Dental Care 2003;9:10.

2. Going RE, Loesche WJ, Grainger DA, Sted SA. The viability of micro-organisms in carious lesions five years after covering with a fissure sealant. J Am Dent Assoc 1979;97:455-462.

3. Mertz-Fairhurst EJ, Schuster GS, Fairjurst CW. Arresting caries by sealants: results of a clinical study. J Am Dent Assoc 1986;112:194-197.

4. Brown LJ, Wall TP, Lazar V. Trends in total caries experience: permanent and primary teeth. J Am Dent Assoc 2000 Feb;131(2):223-231.

5. Kaste LM, Selwitz RH, Oldakowski RJ, Brunelle JA, Winn $\mathrm{DM}$, Brown LJ. Coronal caries in the primary and permanent dentition of children and adolescents 1-17 years of age: United States, 1988-1991. J Dent Res 1996;75:631-641.

6. Waggoner WF, Siegel M. Pit and fissure sealant application: updating the technique. J Am Dent Assoc 1996 Mar;127:351-361.

7. Al-Sarheed M. Bond strength of 4 sealants using conventional etch and a self-etching primer. J Dent Child (Chic) 2006;73(1):37-41.

8. Torr CP, Balbo P, Gomes JM. Effect of individual or simultaneous curing on sealant bond strength. J Dent Child 2005;721(1):31-35.

9. Al-Sarheed M. Evaluation of shear bond strength and SEM observation of all-in-one self-etching primer used for bonding of fissure sealants. J Contemp Dent Pract 2006;7(2):9-16.

10. Chow LC, Brown WE. Phosphoric acid conditioning of teeth for pit and fissure sealants. J Dent Res 1973;52:1158.

11. Gilpatrick RO, Ross JA, Simonsen RJ. Resin to enamel bond strengths with various etching times. Quintessence Int 1991;22(1):47-49.

12. Guba CJ, Cochran MA, Swartz ML. The effects of varied etching time and etching solution viscosity on bond strength and enamel morphology. Oper Dent 1994;19(4):146-153.

13. Goes MF, Sinhoreti MA, Consani S, Silva MA. Morphological effect of the type, concentration and etching time of acid solutions on enamel and dentin surfaces. Braz Dent J 1998;9(1):3-10.

14. Tulunoglu O, Bodur H, Uctasli M, Alacam A. The effect of bonding agents on the microlekage and bond strength of sealant in primary teeth. J Oral Rehabil 1999;26:436-441.

15. Retief DH. Effect of conditioning the enamel surface with phosphoric acid. J Dent Res 1973 Mar-Apr;52(2):333-341.

16. Lopes GC, Baratieri LN, de Andrada MA, Viera LC. Dental adhesion: present state of the art and future perspectives. Quintessence Int 2002;2(1):22-31.

17. Perdigao J, Edward J, Swift JR. Bonding to enamel and dentin: a brief history and state of art. Quintessence Int 1995;26:95-110.

18. Bottenberg P, Graber HS, Lampret F. Penetration of etching agents and its influence on sealer penetration into fissures in vitro. Dent Mater 1996;12:96-102.

19. Perdigao J, Swift EJ. Fundamental concepts of enamel and dentin adhesion. In: Roberson TM, Heymann HO, Swift EJ Jr, editors. Sturdevant art and science of operative dentistry. 4th ed. Missouri, USA: Mosby Inc; 2002. p. 237-268.

20. Terry DA. Direct application of a nanocomposite resin system: Part 1, the update of contemporary composite materials. Pract Proced Aesthet Dent 2004;16(6):417-422. 
21. Sumita BM, Dong WU, Holmes BN. An application of nanotechnology in advanced dental materials. J Am Dent Assoc 2003;134:1382-1390.

22. Olio G. Bond strength testing-What does it mean? Int Dent J 1993;43:492-498.

23. Fuks AB, Eidelman E, Lewinstein I. Shear strength of sealants placed with non-rinse conditioning compared to a conventional acid etch rinse technique. J Dent Child 2002;69: 233,239-242.

24. Sharaf AA. The shear bond strength and microleakage of pits and fissure sealant bonded tooth enamel using three different self etching primers. J Egypt Dent Assoc 2005;51:267.

25. Barroso JM, Torres CP, Lessa FCR, Pécora JD, Palma RG, Borsatto MC. Shear bond strength of pits and fissure sealant to saliva-contaminated and non contaminated enamel. J Dent Child 2005;72:95-99.

\section{ABOUT THE AUTHORS}

\section{Nitin Singh (Corresponding Author)}

Senior Lecturer, Department of Pedodontics and Preventive Dentistry Saraswati Dental College and Hospital, Lucknow, Uttar Pradesh, India e-mail: nitinpedopost@yahoo.in

\section{Govind Agrawal}

Senior Lecturer, Department of Conservative Dentistry and Endodontics, Dr. Hedgewar Smruti Runna Sewa Mandal's Dental College and Hospital, Hingoli, Maharashtra, India

\section{AV Subhash}

Reader, Department of Oral and Maxillofacial Pathology, Sree Sai Dental College and Research Institute, Srikakulam, Andhra Pradesh, India

\section{S Suneela}

Reader, Department of Oral and Maxillofacial Pathology, Sree Sai Dental College and Research Institute, Srikakulam, Andhra Pradesh, India

\section{Aparna S Barabde}

Professor and Head, Department of Prosthodontics, VYWS Dental College and Hospital, Amravati, Maharashtra, India

\section{G Ajay Kumar}

Reader, Department of Prosthodontics, Army College of Dental Sciences, Secunderabad, Andhra Pradesh, India 